\title{
A Contribuição da Análise Científica ao Estudo da Administração: A Teoria das Decisões \\ Richard S. Hillman*
}

1. Introdução. 2. Algumas Abordagens Básicas. 3. A Teoria de Herbert Simon. 4. Aplicação da Teoria ao Desenvolvimento. 5. Administração na América Latina.

"O crescimento de nosso conhecimento factual, juntamente com o esfôrço para uma concepção teórica unificada, compreendendo todos os dados empíricos, conduziu à presente situação que é caracterizada a despeito de todo o seu êxito - por uma incerteza referente à escolha dos conceitos teóricos básicos." - Albert EInstein, Princeton, Nova Jérsei, 10 de setembro de 1948.

\section{Introdução}

E fundamental para o estudo da Administração, a questão já bastante discutida, que indaga se o processo decisório é, ou pode ser, corretamente considerado como científico. E nossa intenção mostrar, face a uma análise das opiniões de renomados autores, que o processo de escolha entre alternativas pode ser cientîficamente estudado.

Uma proposição fundamental dêste artigo é que, se o processo decisório não fôsse passível de análise científica, a teoria administrativa não seria relevante fora dos domínios culturais onde é elaborada. Inversamente, se o processo pode ser estudado cientificamente, então o estudo do comportamento administrativo é tão válido para as sociedades em desenvolvimento quanto o é para as já desenvolvidas. A natureza da análise científica transcende fronteiras nacionais.

* A. B., Diploma de Estudios Hispánicos, Ph. D. O Professor Hillman encontra-se atualmente no Brasil lecionando e pesquisando na Escola de Administração de Emprêsas de São Paulo, da Fundação Getúlio Vargas, sob os auspícios do Latin American Teaching Fellowships Program e o Programa de Fullbright-Hays Travel Grants, é formado pelas Universidades de Nova Iorque, Madri, Bates College e Glasgow.

R. Adm. Emp., Rio de Janeiro, 10 (2): 141-156, abr./jun. 1970 
Além do mais, a neutralidade implícita em uma análise científica possibilita uma abordagem livre de compromissos no que se refere aos problemas de desenvolvimento. Desta forma a abordagem teórica exclui as tentativas espúrias de considerar as instituições de uma sociedade como superiores e universalmente aplicáveis.

Assim, a teoria é um veículo por meio do qual os métodos administrativos podem ser melhor adaptados às metas e condições políticas, econômicas e sociais peculiares aos países em desenvolvimento. Como diz Fred Riggs “... é tão falacioso pensar que os países em transição possam ou devam adotar integralmente as mais recentes técnicas políticas e administrativas dos países mais desenvolvidos, como pensar que êles devam passar pelos mesmos estágios de mudança experimentados, nos séculos XVIII ou XIX, pelas nações ocidentais".'

A teoria científica é um sistema ordenado que seleciona alguns aspectos da realidade e ignora outros, a fim de compreender relações: é uma suposição ordenada acêrca de relações sujeita a ser validada ou invalidada empìricamente.

Modelos ou imagens são usados em tôda pesquisa ou especulação social. A teoria a respeito das decisões não é uma exceção. Consequientemente, tem havido várias tentativas de estabelecer modelos de organização ou padrð̃es conceituais para definir relações decisórias.

\section{Algumas Abordagens Básicas}

E requisito básico de qualquer discussão científica a definição, a classificação e a delimitação dos elementos pertinentes à matéria estudada. E imprescindível, portanto, que façamos a esta altura, uma referência direta aos vários esquemas analisados.

No que se refere a SiMON, por exemplo, temos que para os objetivos dêste artigo não é necessária uma análise minuciosa de sua teoria, mas, sim, a consideração dos aspectos básicos expostos em seu livro o Comportamento Administrativo. ${ }^{2}$

Neste livro, Simon descreve o comportamento administrativo visando a definir os elementos abstratos que aparecem universalmente em

1 Riggs, Fred W. Administration in Developing Countries: The Theory of Prismatic Society. Boston, Houghton-Mifflin, 1964.

2 Simon, Herbert. O Comportamento Administrativo. Rio de Janeiro, Fundação Getúlio Vargas, 1965. 
qualquer tipo de administração, seja ela pública ou privada e demonstra que o processo decisório pode ser entendido como sendo "o coração de Administração".

Afirma ainda que o processo decisório pode ser analisado cientificamente. Equivale a dizer que os elementos básicos do processo se definem como categorias. Contudo, é necessário se entender o caráter desta abstração: embora o processo decisório nem sempre seja um processo racional, êle pode ser abordado racionalmente. Este entendimento é fundamental à tese de SIMON.

Segundo êste esquema, a decisão é uma conclusão baseada na escolha entre conjuntos alternativos de premissas. Algumas premissas se referem a categorias de fato e outras a categorias de valor. A distinção entre o que é fato e o que é valor é considerada uma distinção entre elementos abstratos.

Assim, bàsicamente, a abordagem de SIMON não é uma teoria empírica (os fatos e valôres não são separados orgânicamente). É na realidade uma hipótese funcional.

Antes, porém, de tentarmos uma ilustração desta relação entre fatos e valôres é necessária uma comparação da abordagem científica, com as abordagens de autores que não se utilizam do método científico no estudo do processo decisório e que discordam de Herbert StMon; entre êles figuram J. Pfiffner, R. Presthus, W. Gore, Martin Shubik, Burton Dean e Edward Banfield.

Pfiffner e Presthus sustentam que, embora a principal função do administrador seja tomar decisões, o processo decisório organizacional é um "processo institucionalizado" no qual as decisões são frequientemente "referendadas" pelo administrador, depois que os elementos de linha e de staff, já tenham considerado a questão. Assim, como proposto pelos citados autores, o "tomador de decisões" defrontar-se-ia com os problemas relativos à falta de informações, a conflitos de valor, e mesmo com o conceito de relatividade, se considerarmos que vivemos em um "universo contingente". Tal argumentação leva-nos à idéia de que a escolha puramente racional enfrenta muitos obstáculos. E a existência de fatôres não racionais retiraria então do processo qulaquer pretensão à ciência. 
Ademais, "ao nível teórico, deve-se ressaltar que o processo decisório exige uma constante ultra-simplificação da realidade". 3 Assim, PfiffNer e Presthus concluem que, "como a história tem retratado o homem que toma decisões como uma máquina de calcular, a presente ênfase sôbre sua limitada racionalidade, talvez seja uma compensação necessária". ${ }^{4}$ Porém, à semelhança do que ocorre quando se soma um três positivo a um três negativo, tal compensação não nos deixa base para irmos adiante. A assim chamada "racionalidade limitada" não é uma justificativa para a irracionalidade, e não refuta ou nega, de qualquer maneira, a aplicação de meios racionais para o estudo do problema. Este tipo de crítica não é verdadeiramente construtivo. Pfiffner e Presthus prosseguem na enumeração de barreiras: ignorância, preconceito, falta de informação, consequiências imprevistas e custos irrecuperáveis. ${ }^{5}$ Fazem a seguir um resumo de suas opiniões afirmando que o processo decisório é "inerentemente incapaz de atingir uma completa racionalidade". ${ }^{6}$ Tal conclusão, porém, não ajuda a esclarecer qual o lugar da ciência no campo da Administração. Evidentemente, os fatôres enumerados e expostos por FFIFFNER e Presthus são válidos, mas não nos conduzem mais perto de uma classificação de fatôres operativos em cada decisão. Não há métodos nem hipóteses nesta abordagem. Provàvelmente alguns cientistas sociais não estejam propondo corretamente as questões, o que nos permite, agora, aquilatar melhor a importância das palavras de AlBERT Einstein. O princípio da "incerteza" de Heisenberg também conduz a uma compreensão adequada da análise científica, ao afirmar que a possibilidade de predizer aumenta na proporção inversa das dimensões no campo analisado".

Ao determinar-se, exatamente como um conceito abstrato de tomada de decisão pode ser abordado cientîficamente, o que se deve considerar são as descrições reais do processo decisório: aquelas que destacam as qualidades e os elementos que podem ser aplicados categòricamente a qualquer decisão.

WILlian GORE apresenta algumas opinióes sôbre o que seja o processo decisório. Suas conclusões derivam de um estudo empírico que analisa trinta e três casos de decisão entre dezoito departamentos fe-

3 Pfiffner \& Presthus, p: 115.

4 Ibid., p. 117.

5 Sunk costs, no original.

6 Ibid., p. 120. 
derais do estado de Washington. ${ }^{7} \mathrm{O}$ estágio inicial é a percepção ou verificação da necessidade de mudança. A seguir temos a interpretação ou consideração das alternativas. A terceira etapa é a Luta pelo Poder ou negociação para fins de apoio. Finalmente, temos o que GoRE chama de Formalização. Ele sustenta, inerentemente, que tal processo é institucionalizado e capaz de produzir mudança organizacional.

Tal descrição do processo decisório, enquanto provàvelmente bastante acurada, não leva em consideração os elementos reais ou partes componentes de uma decisão, sendo desta forma, uma descrição incontestável das fases superficiais do processo. Dizer que a água é um líquido cristalino, não equivale a dizer que ela se compõe de duas partes de hidrogênio e uma de oxigênio. $O$ que Gore fêz foi descrever a aparência, e não os elementos essenciais da decisão. Quando lidamos com qualquer conceito devemos abstrair o conjunto de características que o definem, pois de outro modo, o conceito permanece obscuro. $\mathrm{O}$ conceito tomada de decisão continua a exigir esclarecimentos.

Edward C. Banfield opõe-se frontalmente a Herbert Simon alegando que êste leva demasiadamente longe a clareza conceitual, o refinamento metodológico ou mesmo o método cienfífico. ${ }^{8}$ Ele acusa explìcitamente a SiMON de pedantismo, por usar temas em voga, elaborados ao gôsto da moda. BANField dá-nos a impressão de interessar-se mais por semântica do que por idéias! Entretanto, êle admite a intenção de SimON de "trazer uma contribuição metodológica". A intenção de BANFIELD foi mostrar que os três pontos principais de SIMON não fornecem qualquer base operacional para uma ciência adequada.

BANFIELD argumenta que ao invés de princípios reais, o que se tem são provérbios: que os critérios são ambíguos; e que a pesquisa empírica não é possível (não há experiência controlada). Porém, SIMON não está apresentando uma teoria empírica, mas, apenas, certas hipóteses operacionais.

Herbert Simon responde apropriadamente. ${ }^{9}$ Banfield acha necessário abandonar o método científico e voltar ao senso comum, devido ao fator incerteza e à ausência de metas. Isto não se conclui lògica-

7 Decision-Making in Federal Field Offices, 16. Public Administration Review, outono 1956, p. 281-291.

8 Public Administration Review, 17, outono 1957, p. 278-285.

9 Public Administration Review, 18, inverno 1958, p. 60-63. 
mente. Como a ciência moderna tem mostrado (ver a citação de EINSTEIN, na página 1), o senso comum não é senso um de seus instrumentos. Ademais, como Einstein e Heisenberg demonstraram, não há universalidade nos teoremas ou leis criados pelo homem. "Estudar cientificamente os assuntos" diz Simon, "é um caminho íngreme e árduo, porém o único, estou convencido, que nos leva ao nosso objetivo". As críticas de BANFIELD poderiam, realmente, ser aplicadas a qualquer ciência moderna. Portanto, a importância de saber o que se deva considerar como nosso objetivo não pode ser negligenciado, como se fôsse uma discussão sofística."

A certeza de que a ciência pode explicar como as coisas acontecem começou a obscurecer-se cêrca de vinte anos atrás. E, no momento, indaga-se se o homem científico está de fato em contacto com a realidade, ou mesmo, se pode vir a estar. ${ }^{10}$

Respondendo às críticas de BANFIELD, SIMON conclui acertadamente que "o Sr. Banfield tem muito a dizer sôbre o que discorde; mas pouco a dizer sôbre o que defende" ... "O que o Sr. Banfield quer mostrar, é que a mudança da utilização do têrmo maximizer para satisficer, como reconhecimento de que as organizações podem apresentar múltiplos e incomensuráveis objetivos, acrescenta mais um elo ao processo, que vai das proposições de uma ciência pura ou sociológica de administração, até a recomendação de diretrizes na ciência aplicada de administração".

Como em qualquer nôvo campo de estudo, existem apelos para o saber intuitivo, mas, com o desenvolvimento do conhecimento - a prática administrativa virá a se basear amplamente no conhecimento cientificamente testado de mecanismos fundamentais subjacentes. (Este fato, contudo, não conduz a uma completa possibilidade de utilização de computadores, como veremos.)

Desta forma, os rumos desta análise do processo decisório em Administração orientam-se definitivamente no sentido de uma apreciação das hipóteses de Simon. Antes disso, porém, devemos considerar mais dois exemplos da literatura nesta área.

Em Studies and Theories of Decision-Making, MARTIN ShUBIK procura defender uma abordagem multidisciplinar. Relaciona, então, as

10 BARnETt, Lincoln. The Universe \& Dr. Einstein. Mentor, Nova Iorque, 1960. 
"constantes envolvidas na escolha entre alternativas. A primeira delas indica que as decisões grupais são mais importantes que as escolhas individuais; a segunda, que o processo é contínuo podendo ser ocasional ou profundo dependendo das circunstâncias; a terceira, que em pesquisa operacional devemos trabalhar com sistemas dinâmicos; a quarta, que os aspectos não racionais do processo decisório precisam ser considerados; finalmente, que ao se considerar os cursos alternativos de ação, as expectativas confundem-se muito com esperanças. Como conseqüência, conclui SHuBIK, $O$ Homem Econômico recoloca o conceito de SIMON de satisfacing man em uma posição extrema. Argumentaria, ainda, que devido àquelas constantes, o homem não pode decidir na base de suficiência mas sim de esperança para maximizar os resultados.

Burton D. Dean em Application of Operations Research to Decision-Making argumenta que os critérios empregados em pesquisa operacional, são válidos para o estudo da escolha entre alternativas. Os elementos de pesquisa operacional são: orientação, conceitos matemáticos, técnicas analíticas e numéricas aplicadas a um modêlo de pesquisa (o modêlo é uma representação parcial da realidade), e solução (a solução testada é transformada em um conjunto de procedimentos operacionais). A partir dêstes elementos, DEAN traça duas generalizações sôbre o processo decisório. A primeira indica que, antes que o pesquisador possa esperar resolver o seu problema com êxito, é necessário que estejam perfeitamente definidas as circunstâncias que envolvem o tomador de decisão, as informações e alternativas que possui, bem como os seus objetivos. E a segunda é que "o processo decisório realiza-se sempre em circunstâncias de informações imperfeitas, fragmentárias e errôneas".

Mesmo após uma análise profunda dos conhecimentos acima considerados, não estamos ainda em condições de chegar a uma conclusão adequada, no que concerne ao lugar ocupado pela ciência no campo da administração, e, em especial, no tocante ao processo decisório. Isto se deve ao fato de que nem Pfiffner e Presthus, nem Gore recorreram verdadeiramente às regras da ciência. BANFIELD rejeitou a possibilidade de proceder desta forma e nem SHUBIK ou DEAN afastam a ambigüidade do assunto. Como consequiência, tal literatura embora interessante e informativa, não pode ser considerada como teoria. Sabemos que existem muitos tipos de decisão, mas não encontramos nenhuma proposição clara, precisa, sôbre aquelas qualida- 
des comuns a tôdas elas. As proposições ambíguas não podem ser verificadas e, portanto, a significação do processo decisório não está colocado cientificamente em questão. O domínio teórico da indagação científica preocupa-se com os significados. Qual é o sentido do conceito abstrato decisão? Qual o seu conjunto de características definidoras? Para responder a essas perguntas devemos voltar às hipóteses, à ciência. Precisamos recorrer aos princípios, mas sempre à luz das afirmações de EINSTEIN, pois não existe nenhum conjunto de princípios que contenha verdades universalmente válidas. Um mais um são sempre dois, mas uma gôta de água somada a uma outra ainda é uma gôta de água!

Voltando à tese de Herbert Simon, lembramos que êle define o processo decisório como o "coração da administração". A decisão é uma conclusão baseada na escolha entre conjuntos alternativos de premissas. Algumas premissas se referem às categorias de fato e outras, às categorias de valor. "A certeza quando relativa a proposições de ordem moral, só faz sentido em têrmos de valôres humanos subjetivos. A certeza quando relativa a proposições factuais significa verdade objetiva, empírica". ${ }^{11}$ Existem diferentes critérios operativos, da mesma forma como existem diferentes categorias de análise! SIMON "isola certas características do processo decisório e nelas concentra sua atenção apenas para fins de análise... O próprio 'comportamento administrativo' representa uma tentativa de elaboração de um modêlo racional do processo decisório, no sentido de desenvolver um conjunto de conceitos que permitiriam descrições empiricamente válidas, de situações administrativas. O modêlo, portanto, constitui um instrumento para a organização de uma esfera de atividade social, na esperança de dominar sua complexidade. Embora cada modêlo encerre em si mesmo um conjunto de proposições hipotéticas, Simon não apresentou, estritamente falando, uma teoria empírica. Forneceu, isto sim, um número de hipóteses funcionais". ${ }^{12}$

\section{A Teoria de Herbert Simon}

O tema desta análise não exige uma exposição minuciosa dos pontos menos claros da teoria de SrMon. Ao invés de nos "perdermos em

11 Administrative Behavior, p. 53.

12 Concepts and Issues, The Concept of Decision-Making in the Field of Public Administration. Landau, p. 20. 
minúcias", será suficiente um estudo de seus pontos e questões cruciais, para reforçar a argumentação inicial de que o raciocínio científico é um caminho correto para a compreensão do processo decisório. Ademais, é precisamente tal raciocínio que demonstra que o processo de escolha entre alternativas não é, usualmente, científico.

Uma objeção imediata e muito freqüente às formulações de SIMON decorre de suas referências ao positivismo lógico. "As conclusões alcançadas por determinada escola da moderna filosofia - o positivismo lógico - será aceito como um ponto de partida, e suas implicações para a teoria das decisões serão examinadas."13 "O positivismo lógico é baseado na análise de comparações analíticas e sintéticas, bem como de comparações a priori e a posteriori. Estas comparações conduzem à rejeição das afirmações sintéticas a priori e, portanto, excluem as premissas relativas a categorias de valor. A refutação filosófica ao positivismo lógico, entretanto, não nega sua eficiência como instrumento de análise de observações empíricas. SIMON, ao analisar a "estrutura da escolha racional" está observando tanto as premissas factuais como aquelas referentes a valôres. Porém, o relacionamento de uma decisão com um conjunto de objetivos é uma questão factual. Em outras palavras, uma escolha que envolve elementos tanto objetivos quanto subjetivos, pode ser observada de maneira lógica, objetiva e desinteressada, sendo precisamente êstes fatôres, os pontos de partida de uma análise científica.

Muito se tem falado sôbre o que Simon considera como premissas básicas de qualquer decisão. Muita controvérsia origina-se da separação que aparentemente faz entre fatos e valôres. Foi esta "separação" que deu lugar à opinião de que a posição de SIMON é empìricamente inconsistente; na realidade concreta, fatos e valôres estão orgânicamente relacionados não podendo, portanto, serem separados. Novamente, porém, o malôgro em reconhecer o caráter analítico das formulações de Simon é responsável por tal interpretação. SimoN não estava contrariando a realidade, mas sim, tentando distinguir seus vários e essenciais componentes. ${ }^{14}$ À luz desta compreensão, são ilegítimas muitas das conclusões que surgem quando a questão é colocada em têrmos de fato e valor. Além do mais, não se pode argumentar que tal análise sugira a exclusão de juízos de valor no pro-

13 Administrative Behavior, p. 45.

14 Concepts and Issues, The Concept of Decision-Making in the Field of Public Administration. Landau, p. 20. 
cesso decisório. A própria noção de que há não apenas elementos operativos factuais mas também de avaliação, já implica em julgamento. "Quanto mais categorias de valor contenha o processo, maiores serão as incertezas de cada passo a ser dado, e maior importância terão os juízos de valor na determinação de que meios contribuirão para que fins." ${ }^{5}$ P'ortanto, se o caráter analítico das hipóteses de SıMon fôr compreendido na sua perspectiva própria, “... não é a decisão em si mesma que é avaliada, mas a relação puramente factual que aparece entre a decisão e seus objetivos". ${ }^{16}$ Então a questão fatovalor deixa de ser relevante.

Uma questão de maior significado seria aquela orientada para a essência do que Simon tem apreciado: Quais as relações entre os componentes de uma escolha entre alternativas, e o conjunto de objetivos? A resposta foi graficamente representada por THOMPSON e TUDEN: ${ }^{17}$

\section{GRÁFICO 1: Dicotomia Dupla de Decisões}

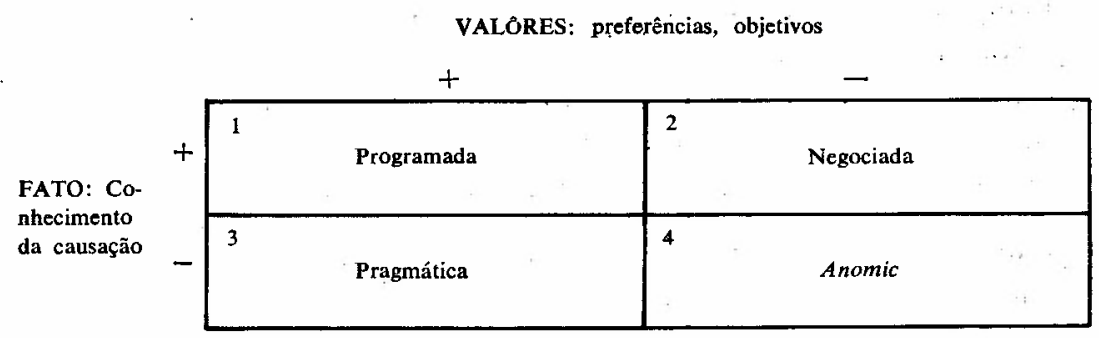

O quadrante 1 representa uma concordância completa no que se refere às metas, bem como um total conhecimento de como atingi-las. No quadrante 3 , há concordância sôbre o que sejam os fins mas não há conhecimento suficiente sôbre os meios. No quadrante 2 , as relações causais são conhecidas mas não há concordância quanto ao valor das mesmas. O quadrante 4 representa uma área na qual não há concordância nem com relação aos fatos, nem com relação a valôres. As áreas as quais cada tipo de decisão corresponderiam, estão sugeridas neste esquema.

Por exemplo, no primeiro quadrante, as decisões não apresentam problema; qualquer tipo de funcionário sabe os seus objetivos: levar

\footnotetext{
15 Administrative Behavior, p. 51.

16 Ibid., p. 49.

17 Thompson, James D. \& Tuden, Arthur. Strategies, Structures and. Processes of Organizational Decision. In: Comparative Studies in Administration, Pittsburgh, 1959.
} 
avante um trabalho. Além disso, êle foi selecionado (ou treinado) por seus conhecimentos de como realizar as tarefas de sua especialização (desta forma o número de aspectos desconhecidos é quase nulo). Da mesma forma as decisões neste quadrante se prestam à utilização de computadores. No segundo quadrante vemos um problema com relação à preferência. Exemplificando: já podemos chegar à Lua (há suficiente conhecimento da acusação) mas não sabemos exatamente o que fazer lá. No terceiro quadrante há concordância com relação aos valôres mas não há um conhecimento perfeito de como decidir sôbre as causas; exemplificando: há concordância acêrca de que o ar poluído é maléfico para a sociedade, mas há desconhecimento sôbre a maneira de resolver êste problema técnico. Finalmente o quarto quadrante aponta situações onde não podemos nos referir a fatos ou valôres. Um exemplo desta situação seria a política de uma emprêsa que perdeu seu mercado e não sabe como proceder daí por diante.

Desta forma, o problema relativo à necessidade ou não de um movimento no sentido de se implementar sistemas de dados, para a programação das decisões (através de computadores) depende totalmente da área ou domínio da atividade em questão. A análise científica foi, e talvez esteja sendo, consideràvelmente, mal empregada. Como foi amplamente ilustrado, o domínio da atividade humana nem sempre permite conhecer os meios que levam a fins escolhidos e aceitos. As hipóteses de SIMON baseadas em análise científica, ajudam a esclarecer isto (esclarecem também os fatôres operativos e sugerem critérios corretos para a realização de uma escolha). Essas hipóteses, na verdade, parecem sugerir que um grande número de reavaliações é necessário. Mais importante, entretanto, é a verificação de que se as decisṍes forem sòmente negociaçôes, então a administração seria tão sòmente um campo de julgamentos subjetivos. "Afirmar que existem valôres envolvidos em cada decisão não é o mesmo que afirmar que as decisões envolvam sòmente elementos relacionados a valôres." 18

Da mesma forma, o contrário é verdadeiro. As decisões envolvem tanto premissas factuais como de valor.

A praticabilidade de qualquer estudo teórico deve ser medido por critérios apropriados. Talvez qualquer contribuição à compreensão dêsse estudo possa ser considerada como uma atividade prática. Contudo,

18 Administrative Behavior, p. 48. 
todo sistema científico é fechado e portanto as conclusões a que se chega relacionam-se sempre com as delimitações e características da teoria, que são impostas pelo próprio sistema. Portanto, declara SiMon, "aquêle que atua na prática não pode nunca optar por negligenciar fatôres ou consequiências condicionantes, simplesmente porque êstes escapam ao domínio de sua teoria". ${ }^{19}$ Este pensamento sugere novamente uma reavaliação do como, onde e porquê da aplicação na prática, do critério científico.

Simon preferiu fazer uma tentativa de esclarecimento das ambiguidades envolvidas no estudo das decisões administrativas. Ele tem formulado hipóteses, definido seus têrmos e procurado compreender sistemàticamente, através de uma estratégia, aquilo que é, em oposição àquilo que deveria ser. SIMON aceitou, da maneira relevante e significativa, certas consequiências da limitação que acompanham qualquer indagaçâao científica. Em outras palavras, êle tem feito muito mais progresso na análise do processo decisório, do que a maioria de estudiosos que contribuíram para a questão com abordagens mais sofisticadas.

E preciso lembrar que pontes e catedrais foram erigidas antes que se conhecessem os princípios técnicos sôbre os quais se assentam as suas estruturas arquitetônicas. Naturalmente eram construídas com enormes sacrifícios e muitos malogros aconteceram antes que os engenheiros usassem métodos científicos para realizações mais eficientes. $O$ processo de tentativas $e$ erros funciona até que uma compreensão científica seja desenvolvida. E, Herbert Simon, sem dúvida alguma deu um passo amplo e acertado no sentido de uma compreensão mais científica dos fatos administrativos. Além disso, a compreensão que se deriva da análise de Simon é sumamente prática. Através de suas hipóteses é possível abordar problemas contemporâneos tais como os relativos à organização administrativa, à investidura de autoridade, à centralização e descentralização, à dicotomia entre a política e a administração, etc.

\section{Aplicação da Teoria ao Desenvolvimento}

Por exemplo o modêlo de burocracia de MAX Weber complementa o paradigma de Simon relativo ao processo decisório, ao descrever o 19 Ibid. p. 70. 
contexto organizacional dentro do qual as decisões são racionais em uma sociedade desenvolvida.

Tais construções conceituais do tipo ideal são medidas que permitem verificar até que ponto a realidade se aproxima de um determinado padrão.

O tipo ideal de burocracia é caracterizado por:

- papéis administrativos altamente diferenciados, especializados;

- recrutamento baseado no mérito e não em preferências pessoais;

- colocação, transferência e promoção baseadas em critérios universais ao invés de critérios particulares;

- administradores profissionais que fazem de seu trabalho uma carreira;

- um processo decisório administrativo dentro de um contexto de hierarquia, responsabilidade e disciplina, racional e prontamente compreendido.

A especialização e a perícia (expertise) que conduzem à diferenciação de funções dentro de organizações administrativas, são compreendidas como sendo aquêles fatôres que tornam legítimas as decisões administrativas. $O$ que distingue o nível de desenvolvimento das instituições administrativas, de uma sociedade, em relação a outra, é o fundamento sôbre o qual a decisão é válida. Desta forma, o desenvolvimento é um processo contínuo e sistemas administrativos podem ser comparados pela verificação da extensão em que a autoridade do conhecimento e da perícia fazem parte das decisões. Isto é, uma escala pode ser construída entre extremos: sociedades desenvolvidas e subdesenvolvidas.

Seria ilegítimo, por exemplo, considerar qualquer organização típica dos Estados Unidos como ideal para a América Latina devido às diferenças culturais e históricas entre duas sociedades. Porém, um tipo ideal que postule características abstratas de uma organização hipotética, pode ser útil para comparações entre culturas. Desde que o paradigma é uma construção teórica êle transcende condições culturais específicas e pode ser usado como medida. 


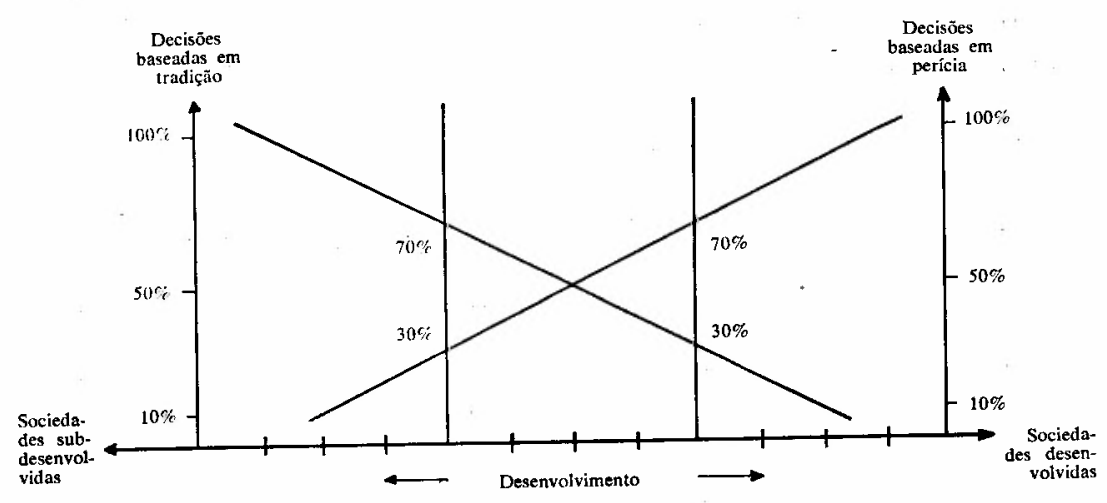

Assim o inter-relacionamento entre fatos e valôres determina as bases teóricas sôbre as quais uma decisão administrativa é legitimada, determina também a estrutura organizacional dentro da qual a decisão é, na maior parte das vêzes, feita de maneira ótima, e ainda o grau relativo do desenvolvimento que caracteriza as instituições administrativas de qualquer sociedade particular. Isto se segue das proposições de SIMON segundo as quais as decisões são combinações tanto de premissas factuais como premissas de valor.

Onde as premissas de valor predominam, a decisão pode ser tratada como julgamento de valor, e onde as premissas factuais predominam, a decisão pode ser tratada como um julgamento de fatos.

$\hat{E}$ interessante ressaltar aqui, que tanto numa sociedade desenvolvida, como numa sociedade tradicional, uma decisão do tipo ideal tem como característica ser passível de programação e computação. Na sociedade tradicional a tradição proscreve a experimentação; na sociedade desenvolvida, os fatos, quando conhecidos, determinam a ação. De acôrdo com Lucian Pye, "A essência do que entendemos como vida moderna... é baseada em um modo de ver científico e racional, e na aplicação em tôdas as fases da vida de um sempre crescente grau de tecnologia. E a reflexão de uma sociedade urbana e industrial na 
qual as relações humanas são postuladas em considerações seculares no lugar de considerações de caráter sagrado". ${ }^{20}$

Na sociedade moderna, é sôbre o conhecimento e a experiência, que a premissa legítima está fundada. Segundo Martin LANDAN, "é porque a experiência se constitui num 'conjunto aberto', no qual hipóteses, experimentos, tentativas e erros... tudo se torna um modo necessário de comportamento. Em verdade, em face da incerteza, êles são tomados tanto como um processo como um requisito de um processo decisório". ${ }^{21}$

Numa sociedade tradicional, entretanto, êstes modos de conduta são ilegítimos: êles são pecaminosos e representam heresia.

\section{Administração na América Latina}

A experiência da América Latina sugere um movimento de saída que foi chamado "a velha ordem" em direção às diversas idéias de como nações desenvolvidas devam ser. Assim, os problemas de desenvolvimento da América Latina podem ser compreendidos em têrmos de repúdio a sistemas tradicionais, concomitante e transição para uma nova ordem. Fôrças tradicionais operam em justaposição com fôrças de mudança. Assim, a América Latina se localiza em algum lugar entre dois tipos ideais.

Como sociedades em transição, as nações em desenvolvimento da América Latina retêm certos valôres tradicionais e escapam de outros. Neste contexto o requisito para o desenvolvimento é a criação de uma estrutura cultural a qual permita que variáveis empíricas desempenhem um papel de maior importância nos procedimentos do processo decisório.

Até que possamos contar com decisões técnicas e programação experimental, não haverá conceito de administração como uma variável independente. Desde que as sociedades em transição tenham necessidade de estabelecer hipóteses de planejar e de mudar, a teoria administrativa deve focalizar o processo decisório e a organização administrativa, como assuntos apropriados da análise científica.

20 Py, Lucian W. The Concept of Political Development. The Annals, volume 358, 1965, p. 19.

21 Landau, Martin. The Concept of Decision-Making in the Field of Public Administration. In: MAILICK e VaN Ness (eds.). Concepts and Issues in Administrative Behavior. Englewood, Prentice Hall, 1962, p. 50. 


\section{Bibliografia}

AYER, A. J. Language, Truth and Logic. Londres, Victor Gollancz, 1936.

BARNETT, Lincoln. The Universe and Dr. Einstein. Nova Iorque, Mentor, 1960.

Geymonat, Ludovico. Filosofía y Filosofía de la Ciencia. Barcelona, Nueva Collección, 1965.

MAILICK, S. \& VAN NESS, E. Concepts and Issues in Administrative Behavior. Nova Iorque, Prentice-Hall, 1962.

Pfiffner, J. \& Presthus, R. Public Administration, Nova Iorque, Ronald Press, 1960.

RIGGS, Fred W. Administration in Developing Countries: Theory of Prismatic Society. Boston, Houghton Mifflin, 1964.

Simon, Herbert. Administrative Behavior, Nova Iorque, Free Press, 1965.

Banfield, Edward. The Decision-Making Schema. Public Administrative Review, 1957, p. 278-285.

BENNIS, W. G. Leadership Theory and Administrative Behavior. Administrative Science Quarterly, vol. 4, dezembro de 1959.

Pye, Lucian W. The Concept of Political Development. The Annals, vol. 358, 1965 , p. 19.

Simon, Herbert. The Decision-Making Schema, A Reply. Public Administration Review, 1958, p. 60-63.

Thompson, J. D. \& Tuden, Arthur. Strategies, Structure and Processes of Organizational Decision. Comparative Studies in Administration. Pittsburgh, 1959.

Quando foi descoberta a cura do câncer?

O Correio da UNESCO, em $n^{\circ}{ }^{\circ}$ especial sôbre o câncer, revela que os métodos atuais de erradicação da moléstia já conseguiram curar mais de $50 \%$ dos pacientes.

Leia ainda: A Importância do diagnóstico precoce e O Fumo e o câncer.

Pedidos para a Fundação Getúlio Vargas, Serviço de Publicações, Praia de Botafogo 188, C. P. 21.120, ZC-05, Rio, GB. 